\title{
Study of Preoperative Indicators of Ossicular Defect in Mucosal Type of Chronic Suppurative Otitis Media
}

\author{
Vivek Vishwas Harkare' ${ }^{1}$, Sonali Prabhakar Khadakkar², Nitin Vasant Deosthale ${ }^{3}$ Priti Rakesh Dhoke4, \\ Kanchan Sandeep Dhote ${ }^{5}$, Komal Arun Kakad ${ }^{6}$, Priyal Vardhaman Patil7, Shivani Suresh Pidurkar ${ }^{8}$
}

\begin{abstract}
${ }^{1}$ Department of ENT, NKP Salve Institute of Medical Sciences, Nagpur, Maharashtra, India. ${ }^{2}$ Department of ENT, NKP Salve Institute of Medical Sciences, Nagpur, Maharashtra, India. ${ }^{3}$ Department of ENT, NKP Salve Institute of Medical Sciences, Nagpur, Maharashtra, India. ${ }^{4}$ Department of ENT, NKP Salve Institute of Medical Sciences, Nagpur, Maharashtra, India. ${ }^{5}$ Department of ENT, NKP Salve Institute of Medical Sciences, Nagpur, Maharashtra, India. ${ }^{6}$ Department of ENT, NKP Salve Institute of Medical Sciences, Nagpur, Maharashtra, India. ${ }^{7}$ Department of ENT, NKP Salve Institute of Medical Sciences, Nagpur, Maharashtra, India. ${ }^{8}$ Department of ENT, NKP Salve Institute of Medical Sciences, Nagpur, Maharashtra, India.
\end{abstract}

\section{ABSTRACT}

\section{BACKGROUND}

Ossicular defect is although more common in squamosal type of chronic suppurative otitis media, it can also occur in mucosal type of the disease. Its preoperative knowledge not only helps surgeon to plan for ossicular reconstruction in a better way but also to counsel the patient accordingly. We wanted to determine the prevalence of ossicular chain defect and preoperative identification of clinical and audiological factors as indicators of ossicular defects in patients with Mucosal CSOM.

\section{METHODS}

This is a hospital based cross sectional study of 2 years. Patients 15 to 60 years of age, having inactive mucosal type of Chronic Suppurative Otitis Media, posted for Tympanoplasty were included in the study. Findings on history, clinical, audiological and intraoperative otomicroscopic examination were recorded and analysed.

\section{RESULTS}

Ossicular necrosis was noted in 21 (23.33\%) of total 90 patients. On statistical analysis, patients of age $>30$ years $(p=0.019$, duration of ear discharge $>10$ years $(p=0.003)$, those having large and subtotal perforation $(p<0.001)$, adhesion of tympanic membrane edges to promontory $(\mathrm{p}=0.04)$, incudostapaedial joint area exposure $(\mathrm{p}=0.01)$ and air-one gap $>40 \mathrm{~dB}(\mathrm{p}<0.001)$ were found to be statistically significantly associated with ossicular erosion.

\section{CONCLUSIONS}

All patients of mucosal type of chronic suppurative otitis media should be assessed in detail so as to get a clue of ossicular defects to be prepared for its repair and will not come as a surprise during surgery.

\section{KEY WORDS}

Chronic Suppurative Otitis Media, Ossicular Necrosis, Air-Bone Gap
Corresponding Author: Dr. Sonali Prabhakar Khadakkar, \#39, Shivaji Housing Society, Near Shri Chawadeshwari Mandir, New Subhedar Nagar, Nagpur-440024, Maharashtra, India.

E-mail: sonalikhadakkar@yahoo.com

DOI: $10.14260 / \mathrm{jemds} / 2020 / 145$

Financial or Other Competing Interests: None.

How to Cite This Article:

Harkare VV, Khadakkar SP, Deosthale NV, et al. Study of preoperative indicators of ossicular defect in mucosal type of chronic suppurative otitis media. J. Evolution Med. Dent. Sci. 2020;9(09):668-672, DOI: 10.14260/jemds/2020/145

Submission 21-12-2019, Peer Review 03-02-2020,

Acceptance 11-02-2020, Published 02-03-2020. 


\section{BACKGROUND}

Chronic Suppurative Otitis Media (CSOM), a common condition in otorhinolaryngology, is characterized by chronic, intermittent or persistent discharge through a perforated tympanic membrane. It leads to a wide range of pathologies in the middle ear that include irreversible mucosal changes, granulation tissue formation, cholesteatoma, tympanosclerosis and ossicular destruction.Ossicular chain involvement is found in both mucosal and squamosal type of disease. Ossicular erosion due to mucosal CSOM may be due to an increased osteoclastic activity or avascular necrosis by means of overproduction of cytokines-tumor necrosis factor (TNF) alpha, interleukin-2, fibroblast growth factor, and platelet-derived growth factor. Thomsen et at stated that, hyperaemia associated with mucosal inflammation rather than avascular necrosis causes osteoclasis resulting in bony erosion. ${ }^{1}$ According to Schachern $\mathrm{P}$ et al, granulation tissue in nondraining spaces of middle ear cleft could result in significant bony erosion over a period of time. ${ }^{2}$

Malleus, incus and stapes along with tympanic membrane are vital for impedance matching mechanism of the middle ear. Necrosis of long process of the incus, Superstructure of stapes, body of incus and manubrium occur in decreasing order of frequency in Chronic Otitis Media. Complete disruption of the ossicular chain can result up to $60 \mathrm{~dB}$ hearing loss. Erosion or Discontinuity of the ossicular chain is confirmed only during surgery. Preoperative High-Resolution Computed Tomography (HRCT) Scan of Temporal bone can give a clue of ossicular integrity. But it's high cost and degree of Radiation exposure limits its use in developing countries like India specially in cases of mucosal type of CSOM. Preoperative knowledge of ossicular discontinuity is important because it enables the surgeon to discuss with the patient the possible outcome of surgery and take the consent accordingly. Surgeon can also plan for ossicular reconstruction operation with respect to arrangement of specific instruments, consumables, prosthesis etc.

Aim of our study was to determine the prevalence of ossicular chain defect and preoperative identification of clinical and audiological factors as indicators of ossicular defects in patients with mucosal type of CSOM.

\section{METHODS}

This was a Cross Sectional Analytical study conducted in the Department of ENT of Tertiary Health Care Institute of Central India from 1st March 2016 to 28 ${ }^{\text {th }}$ Feb 2018. As it was a time bound study, every consecutive patient of mucosal type of Chronic Suppurative Otitis Media (CSOM) fulfilling inclusion criteria were selected for the study. Approval from Institutional Ethics Committee was achieved before starting the study. Patients of either sex and age above 15 years to 60 years having inactive mucosal type of Chronic Suppurative Otitis Media with pure conductive hearing loss and functioning Eustachian tube posted for Tympanoplasty were included in the study. Whereas the patients who were with squamosal type of CSOM and previous history of ear surgery in the same ear were excluded from the study. An informed written consent was taken before the conduct of the study.

The selected patients underwent a detailed clinical examination which included otoscopic and microscopic examination and all findings were recorded. On microscopic examination, when there is permanent central perforation in Pars tensa but no inflammation of middle ear mucosa and no production of pus in the middle ear and mastoid it was diagnosed as Inactive mucosal type of Chronic Suppurative Otitis Media. Perforation of size of a single, two, three or more quadrants of Pars Tensa were classified into small, medium and large perforation respectively and if the entire Pars Tensa involved with intact annulus was considered as subtotal perforation. Preoperative Pure Tone Audiometry was done a day prior to surgery to assess the type and degree of hearing loss using "Elkon EDA Giga 3" Pure Tone Audiometer. The air and bone conduction threshold averages were calculated by taking the average of $0.5-2 \mathrm{k} \mathrm{Hz}$ frequencies. The Air Bone Gap (ABG) was calculated by taking difference between air conduction and bone conduction thresholds. In Pure conductive hearing loss, Bone conduction threshold remains normal ( $-10 \mathrm{dbB}$ to $20 \mathrm{~dB})$, Air conduction threshold is more than $20 \mathrm{~dB}$ with Air- Bone Gap of $>20 \mathrm{~dB}$. The mean Auditory Threshold was classified into $<40 \mathrm{~dB}$ and $>40$ dB. Eustachian Tube Function was assessed by Toynbee's test using Impedance Audiometer "Interacoustics AT 235". In this test, if the increased or decreased middle ear pressure built up by the impedance audiometer is neutralized in 5 swallows in a step ladder pattern then the eustachian tube is labelled as normally functioning. X-Ray both Mastoids Schuller's view was done to know the status of mastoid air cell system.

Pre-anaesthetic evaluation was done to achieve fitness for the surgery. Tympanoplasty was done by post aural approach under Local Anaesthesia with IV sedation or General Anaesthesia whichever was required. Intra-operative middle ear findings including status of middle ear mucosa, ossicular chain status, erosion of the individual ossicle and continuity of the malleo-incudal and incudostapaedial joint were noted. Temporalis fascia was used as graft material for repair of tympanic membrane perforation. Ossicular reconstruction was done in patients with ossicular chain defects by resculpturing the autologous ossicules or by using autologous tragal cartilage graft depending on the defect.

\section{Ethical Considerations}

The permission was taken from Institutional Ethics Committee prior to starting the project. All procedures performed in studies involving human participants were in accordance with the ethical standards of the institutional and/or national research committee and with the Helsinki Declaration of 1975, as revised in 2008.

\section{Statistical Analysis}

Data was entered in Microsoft Office Excel 2010 and was analysed using Epi Info version 7. Frequencies and percentages of categorical variables were calculated. Association between categorical variables was assessed by the $\chi 2$ (chi- square) test. Association between audiogram and ossicular necrosis was analyzed using independent ' $\mathrm{t}$ ' test. $\mathrm{P}$ value $\leq 0.05$ was considered statistically significant. 


\section{RESULTS}

A total of 90 patients with inactive mucosal type of Chronic Suppurative Otitis Media were included in the study with the mean age of $28.59 \pm 10.08$ years with male to female ratio of 1:1.8. Out of 90 patients, $21(23.33 \%)$ had ossicular necrosis detected under operating microscope during surgery.

As shown in Table I, out of 21 patients having ossicular necrosis, 13 had age of more than 30 years and 8 with age below 30 years and this was statistically significant difference with Odd's ratio of $3.203\left(\chi^{2}=5.476, p=0.019\right) .9$ out of 34 males and 12 out of 56 females found to have ossicular erosion and there was no statistically significant difference between males and females with respect to ossicular necrosis $(p=0.61) .23$ patients had CSOM for more than 10 years of which 11 had ossicular necrosis while 10 out of 67 patients having the disease less than 10 years had ossicular necrosis. There was a positive association between duration of disease and ossicular defects, which was statistically significant with the Odd's ratio of $5.23\left(\chi^{2}=10.36, p=0.003\right)$ indicating longer the duration of disease, more chances are of ossicular necrosis (table I).

Association between preoperative Clinical parameters and Ossicular Necrosis was studied as shown in Table II. For statistical analysis purpose, patients with Small (16 patients) and Moderate (37 Patients) perforation clubbed together (53 patients) and shown ossicular necrosis in only 5 patients. Large (20 patients) and Subtotal perforation (17 patients) grouped together (37 patients) out of which 16 patients had ossicular necrosis. The difference in the rate of ossicular necrosis in those two groups was statistically significant $\left(\chi^{2}=\right.$ 13.92, $\mathrm{p}<0.001$, Odd's ratio $=7.13$ ).

On otomicroscopic examination, round window niche was visible through perforation in 47 patients, but proportion of ossicular necrosis (14 patients) was not statistically significant in them $\left(\chi^{2}=2.79, \mathrm{p}=0.13\right)$. Adhesion between margins of Tympanic membrane perforation and promontory was seen in 45 patients of which 15 patients had ossicular necrosis and this was statistically significant correlation $\left(\chi^{2}=\right.$ 5.03, $\mathrm{p}=0.04$, Odd's ratio $=3.25$ ). The incudostapaedial joint area was visible in 37 patients and 14 patients had ossicular destruction with significant relationship $\left(\chi^{2}=7.39, \mathrm{p}=0.01\right.$, Odd's ratio $=4$ ) as shown in Table II.

\begin{tabular}{|c|c|c|c|c|c|c|c|}
\hline \multicolumn{2}{|c|}{ 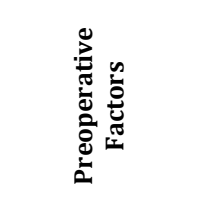 } & \multirow[t]{2}{*}{ 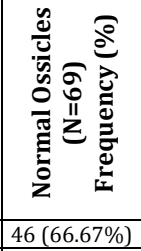 } & \multirow[t]{2}{*}{ 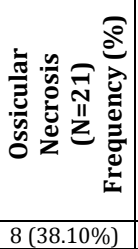 } & \multirow{2}{*}{ 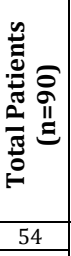 } & \multirow{3}{*}{ 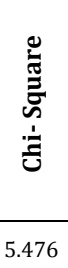 } & \multirow{3}{*}{ 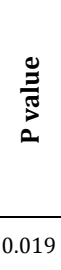 } & \multirow{2}{*}{ 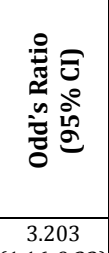 } \\
\hline Age & $<30$ years & & & & & & \\
\hline Age & $>30$ years & $23(33.33 \%)$ & $13(61.90 \%)$ & 36 & & & $(1.16-9.23)$ \\
\hline \multirow[b]{2}{*}{ Sex } & Male & $25(36.23 \%)$ & $9(42.86 \%)$ & 34 & \multirow{2}{*}{3.006} & \multirow{2}{*}{0.61} & 1.32 \\
\hline & Female & $44(63.77 \%)$ & $12(57.14 \%)$ & 56 & & & $(0.48-3.5)$ \\
\hline \multirow{2}{*}{$\begin{array}{c}\begin{array}{c}\text { Duration } \\
\text { of } \\
\text { Disease }\end{array} \\
\end{array}$} & $<10$ years & $57(82.61 \%)$ & $10(47.62 \%)$ & 67 & \multirow[b]{2}{*}{10.36} & \multirow[b]{2}{*}{0.003} & \multirow{2}{*}{$\begin{array}{c}5.23 \\
(1.81- \\
15.06)\end{array}$} \\
\hline & $>10$ years & $12(17.39 \%)$ & $11(52.24 \%)$ & 23 & & & \\
\hline \multicolumn{8}{|c|}{$\begin{array}{c}\text { Table I. Association of Baseline Characters of } \\
\text { Patients with Ossicular Necrosis }(n=90)\end{array}$} \\
\hline
\end{tabular}

Air- Bone Gap of $\leq 40 \mathrm{~dB}$ was seen in 66 patients, of which $62(89.85 \%)$ patients had normal ossicles. In contrast, greater proportion of patients (17 out of 24 patients) with Air- Bone Gap of $>40 \mathrm{~dB}$ shown ossicular necrosis $(\mathrm{p}<0.001$, highly significant) (table II). Mean ABG of study population ( $\mathrm{n}=90$ ) was $40.58 \pm 9.05$ dB. 69 patients with normal ossicles had Mean Air- Bone Gap (ABG) of $37 \pm 3.76 \mathrm{~dB}$ and 21 patients with ossicular necrosis found to have ABG of $52.32 \pm 4.50 \mathrm{~dB}$ and the difference was statistically significant. (independent t-test= 15.60, p< 0.001). (table III)

We evaluated the hearing loss associated with different types of ossicular defects (table 4). Out of 21 cases with ossicular necrosis, Long process of incus necrosis was seen in maximum number of cases (10 cases) and average hearing loss of this group was $50.56 \mathrm{~dB}$. The involvement of long process of incus and super structure of stapes was seen in 4 cases and average hearing loss was $56.52 \mathrm{~dB}$. Necrosis of isolated lenticular process, Necrosis of Handle of Malleus with Long process of Incus and that of all three ossicles was seen in 2 patients each. Isolates Handle of Malleus erosion was seen in only one patient. Maximum hearing loss was seen in patients with necrosis of all the three ossicles (average $\mathrm{ABG}=59.54 \mathrm{~dB}$ ) (table IV).

\begin{tabular}{|c|c|c|c|c|c|c|}
\hline \multicolumn{2}{|c|}{ 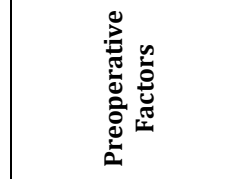 } & 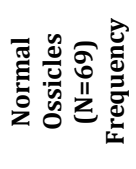 & 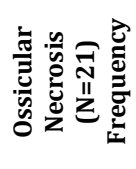 & 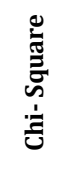 & $\frac{0}{3}$ & 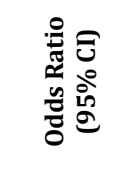 \\
\hline \multirow{2}{*}{$\begin{array}{l}\text { Size of } \\
\text { perforation }\end{array}$} & $\begin{array}{c}\text { Small \& } \\
\text { Moderate }\end{array}$ & $48(69.57 \%)$ & $5(23.80 \%)$ & \multirow{2}{*}{13.92} & \multirow{2}{*}{$<0.001$} & \multirow{2}{*}{$\begin{array}{c}7.13 \\
(2.37-24.33)\end{array}$} \\
\hline & $\begin{array}{l}\text { Large \& } \\
\text { Subtotal } \\
\end{array}$ & $21(30.43 \%)$ & $16(76.19 \%)$ & & & \\
\hline \multirow{2}{*}{$\begin{array}{c}\text { Round } \\
\text { Window } \\
\text { Exposure }\end{array}$} & Yes & $33(47.83 \%)$ & $14(66.67 \%)$ & \multirow{2}{*}{2.29} & \multirow{2}{*}{0.13} & \multirow{2}{*}{$\begin{array}{c}2.18 \\
(0.78-6.06)\end{array}$} \\
\hline & No & $36(52.17 \%)$ & 7 (33.33\%) & & & \\
\hline \multirow{2}{*}{$\begin{array}{r}\text { TM edge } \\
\text { adhesion }\end{array}$} & Yes & $30(43.47 \%)$ & $15(71.43 \%)$ & \multirow{2}{*}{5.03} & \multirow{2}{*}{0.04} & \multirow{2}{*}{$\begin{array}{c}3.25 \\
(1.12-9.37) \\
\end{array}$} \\
\hline & No & $39(56.52 \%)$ & $6(28.57 \%)$ & & & \\
\hline \multirow{2}{*}{$\begin{array}{c}\text { IS joint area } \\
\text { exposure }\end{array}$} & Yes & $23(33.33 \%)$ & $14(66.67 \%)$ & \multirow{2}{*}{7.39} & \multirow{2}{*}{0.01} & \multirow{2}{*}{$\begin{array}{c}4 \\
(1.41-11.27) \\
\end{array}$} \\
\hline & No & $46(66.67 \%)$ & $7(33.33 \%)$ & & & \\
\hline \multirow{2}{*}{$\begin{array}{c}\text { Air- Bone } \\
\text { Gap (ABG) }\end{array}$} & $\leq 40 \mathrm{~dB}$ & $62(89.86 \%)$ & $4(19.05 \%)$ & \multirow{2}{*}{41.28} & \multirow{2}{*}{$<0.001$} & \\
\hline & $>40 \mathrm{~dB}$ & $7(10.14 \%)$ & $17(80.95 \%)$ & & & \\
\hline \multicolumn{7}{|c|}{$\begin{array}{c}\text { Table II. Association of Preoperative Clinical Parameters } \\
\text { with Ossicular Necrosis }(n=90)\end{array}$} \\
\hline
\end{tabular}

\begin{tabular}{|c|c|c|c|c|}
\hline & $\begin{array}{c}\text { Normal Ossicles } \\
(\mathbf{N}=\mathbf{6 9})\end{array}$ & $\begin{array}{c}\text { Ossicular Necrosis } \\
(\mathbf{N}=\mathbf{2 1})\end{array}$ & t- Test & p value \\
\hline Mean ABG & $37 \pm 3.76 \mathrm{~dB}$ & $52.32 \pm 4.50 \mathrm{~dB}$ & 15.60 & $<0.001$ \\
\hline Mean Air- Bone Gap (n=90) $=40.58 \pm 9.05 \mathrm{~dB}$ \\
\hline \multicolumn{3}{|c|}{ Table III. Comparison of Mean Air-Bone Gap (ABG) } \\
with Ossicular Status (n=90) \\
\hline
\end{tabular}

\begin{tabular}{|c|c|c|}
\hline Ossicular Necrosis & $\begin{array}{l}\text { Frequency }(\%) \\
(\mathrm{N}=21)\end{array}$ & $\begin{array}{l}\text { Average Hearing Loss } \\
\text { (Mean ABG +/- SD in dB) }\end{array}$ \\
\hline Isolated Lenticular Process & $2(9.52 \%)$ & $49.16 \mathrm{~dB}+/-1.82 \mathrm{~dB}$ \\
\hline Isolated Long Process of Incus & $10(47.62 \%)$ & $50.56 \mathrm{~dB}+/-6.32$ \\
\hline Isolated Malleus Handle & $1(4.76 \%)$ & $44.6 \mathrm{~dB}$ \\
\hline $\begin{array}{l}\text { Malleus Handle and Long } \\
\text { Process of Incus }\end{array}$ & $2(9.52 \%)$ & $52.5 \mathrm{~dB}+/-5.61 \mathrm{~dB}$ \\
\hline $\begin{array}{l}\text { Long process of Incus and } \\
\text { Stapes Super-structure }\end{array}$ & $4(19.05 \%)$ & $56.52 \mathrm{~dB}+/-4.13 \mathrm{~dB}$ \\
\hline All three ossicles & $2(9.52 \%)$ & $59.54 \mathrm{~dB}+/-2.56 \mathrm{~dB}$ \\
\hline \multicolumn{3}{|c|}{$\begin{array}{c}\text { Table IV. Distribution of Patients and Average Hearing Loss } \\
\text { According to Ossicular Necrosis }\end{array}$} \\
\hline
\end{tabular}

\section{DISCUSSION}

Defects of the ossicular chain may occur in all chronic middle ear diseases. Although it is most commonly seen in squamosal type of CSOM, it has been well established that it can also be seen in mucosal type of CSOM.3,4 Ossicular erosion in mucosal type of Otitis media is due to 
hypervascularization, osteoclast activation, and bone resorption by means of overproduction of cytokines like Tumour Necrosis Factor (TNF)- alpha, Interleukin 2, Fibroblast Growth Factor and Platelet Derived Growth factor. CSOM is thus an inflammatory process with a defective wound healing mechanism. ${ }^{5}$ It is more harmful when it stays for longer duration and when it is nearer to the ossicular chain. ${ }^{6}$ Ossicular necrosis more commonly occurs in finely constructed parts of the chain, mainly long process of incus and stapes superstructure where osteoclastic activity is abundant as compared to weak osteoblastic activity. ${ }^{7}$

The ability to predict the presence of ossicular discontinuity in such patient using certain preoperative factors, would be of benefit in allowing the surgeon to plan ahead with regard to the need for an ossiculoplasty and also to give the patient a realistic explanation of the expected outcome. There have been limitations of the microscope during visualization of the posterosuperior area of tympanic cavity and blind niches. Rigid endoscope can be employed to visualize and evaluate the extent of middle ear disease, assess ossicular integrity and explore the hidden niches of the middle ear and provides the surgeon with better control over the pathology and therefore achieves enhanced eradication of disease. ${ }^{8}$ In the present study, ossicular necrosis in inactive mucosal type of CSOM was seen in $23.33 \%$ cases (21 out of 90). Isolated Long process of incus was predominantly affected, i.e. in 11 out of total 21 cases of ossicular necrosis. Austin in his study of 1151 ears with CSOM found incus erosion as commonest type of ossicular defect. ${ }^{9}$ Schuknecht in his histological study of ossicles in CSOM, found frequency of ossicular necrosis in a decreasing order as long process of incus, crura of stapes, body of incus and manubrium of malleus. ${ }^{10}$ Ebenezer J et al in their prospective study on 150 non-cholesteatomatous ears, noted incudal necrosis in 24 (16\%) ears. ${ }^{11}$ While Jayakumar CL et al noted ossicular necrosis in $23.1 \%$ cases (in 16 out of 69 patients) and incus was most commonly ossicle $(62.5 \%)$ followed by malleus(31.2\%) and then stapes $(6.25 \%){ }^{12}$ Srinivas et al noticed ossicular necrosis in only $11 \%$ cases (5 out of 47 patients). ${ }^{13}$ Jeng et al also found ossicular necrosis in $11.1 \%$ (17 out of 153) patients of non-cholesteatomatous ears. ${ }^{4}$ in Tripathi $P$ et al study, Incus necrosis was seen in $22.38 \%$ case of total 67 cases with non-cholesteatomatous ear. ${ }^{14}$ Higher prevalence of ossicular necrosis in our study could be due to long standing disease and repeated episodes of infections leading to progressive ossicular erosion.

On analyzing the relationship between ossicular necrosis and preoperative factors, we found that that patients of age above 30 years and duration of disease for more than 10 years were significant indicators of ossicular necrosis. Jayakumar CL et al noted similar finding on bivariate analysis. ${ }^{12}$ This could be due to negligence of patient to seek early treatment or inadequate treatment. As per Tripathi P et al study, those who had disease for more than 5 years were more were prone for incus necrosis. ${ }^{14}$ According to Chole and Chao, long standing CSOM can lead to the growth of granulation tissue and inflammatory products in the middle ear cleft that leads to significant bone erosion over a period of time. 15

Adherence of perforation edges to the promontory also had significant association with ossicular necrosis ( $p<0.05)$ in the studies of Ebenezer J et al, Jayakumar CL and Srinivas et al studies.[10-12] Our finding was consistent with those studies. Jeng et al concluded that, adhesion causes confinement of inflammatory products and granulation tissue to a small blind sac causing hyperemia and increased pressure on ossicles leading to erosion. ${ }^{4}$ Size of perforation, exposure of Incudostapaedial joint area were other factors showing significant association with ossicular necrosis ( $p$ $<0.05$ ) in the studies by Ebenezer J et al,11 Jayakumar $\mathrm{CL}^{12}$ and also in our study. According to Tripathi $\mathrm{P}$ et al study, incudostapaedial joint was exposed in $32.8 \%$ cases $(n=67)$ had exposed IS out of these, necrosed incus was seen in $14.9 \%$ cases indicating statistically significant association. ${ }^{14}$

In our study, Air- Bone Gap of $>40 \mathrm{~dB}$ was found to be statistically significant preoperative indicator for ossicular necrosis. Similar observations were made by other studies which suggest that raised Pure Tone Audiometric threshold and Air Bone gap of $>40 \mathrm{~dB}$ are good indicators of ossicular defects in mucosal type of CSOM.4,11,12 in Tripathi $P$ et al study, Incus was found necrosed more frequently in patients who had moderate or moderately severe pre-operative hearing loss and the difference was statistically highly significant $(\mathrm{p}=0.001) \cdot{ }^{14}$ According Ingelstedt $\mathrm{S}$ et al study, an ABG of greater than $30 \mathrm{~dB}$ at $2 \mathrm{kHz}$ and greater than $40 \mathrm{~dB}$ at $4 \mathrm{kHz}$ increased the probability of ossicular discontinuity to $89 \%{ }^{16}$ Carillo et al studied Pure Tone Audiometric Thresholds in patients who underwent tympanomastoidectomy and found that a wide Air-Bone Gap at higher frequencies was more suggestive of incus necrosis. ${ }^{17}$ In contrast to this, according to Jeng et al, Air-Bone Gap is not a good predictor of ossicular necrosis as granulations could bridge the defect between eroded ossicles thus reducing the Air-Bone Gap. ${ }^{4}$

Presence of Middle ear granulations was found to be statistically significant predictor for ossicular necrosis in Ebenezer J et al and Jayakumar CL et al studies. ${ }^{11,12}$ While there was no significant association with respect to middle ear polypoidal mucosa with ossicular erosion in Srinivas C et al study. ${ }^{13}$ We could not find granulations in our cases intraoperatively as we included only dry ears in the study which can be the reason for this while other studies included both dry and wet ears.

In our study, sex of patients and round window area exposure were also analyzed but were not found to statistically significantly associated with ossicular necrosis and the finding is consistent with other studies. ${ }^{11,12}$ Menon AG et al found that, visualization of the handle of malleus, long process of incus, incudostapedial joint, stapes supra structure, Eustachian tube opening and the hypotympanum is statistically significantly better with the $30^{\circ}$ and $70^{\circ}$ endoscopes as compared to the microscope and should be incorporated in evaluation of middle ear in cases of CSOM. ${ }^{18}$

\section{CONCLUSIONS}

The risk of ossicular erosion in mucosal type of CSOM is higher, if the disease persists for $>10$ years, if the margin of the perforation is adherent to the promontory and if the airbone Gap is $>40 \mathrm{~dB}$. This can help the surgeon to plan for ossicular reconstruction preoperatively. 


\section{REFERENCES}

[1] Thomsen J, Bretlau P, Jorgensen MB. Bone resorption in chronic otitis media. The role of cholesteatoma: a must or an adjunct? Clinical Otolaryngology Alied Sci 1981;6 (3):179-86.

[2] Schachern P, Paparella MM, Sano S, et al. A histopathological study of the relationship between otitis media and mastoiditis. Laryngoscope 1991;101 (10):1050-5.

[3] Chole RA, Sudhoff HH. Chronic otitis media, mastoiditis and petrositis. In: Naparko JK, edr. Cummings head and neck surgery. Philadelphia: Mosby 2010: p. 1963-78.

[4] Jeng FC, Tsai MH, Brown CJ. Relationship of preoperative findings and ossicular discontinuity in chronic otitis media. Otol Neurotol 2003;24 (1):29-32.

[5] Deka RC. Newer concepts of pathogenesis of middle ear cholesteatoma. Indian J Otol 1998;4 (2):55-7.

[6] Sade J, Berco E, Buyanover D, et al. Ossicular damage in chronic middle ear damage. Acta Otolaryngol 1981;92 (3-4):273-83.

[7] Peake WT, Rosowski JJ, Lynch TJ 3rd. Middle-ear transmission: acoustic versus ossicular coupling in Cat and human. Hear Res 1992;57 (2):245-68.

[8] Ghaffar S, Ikram M, Zia S, et al. Incorporating the endoscope into middle ear surgery. Ear Nose Throat J 2006;85 (9):593-6.

[9] Austin DF. Ossicular reconstruction. Arch Otolaryngol 1971;94 (6):525-35.
[10] Schuknecht HF. Infections: ossicular resorption. In: Schuknecht HF, edr. Pathology of the ear. $2^{\text {nd }}$ edn. Philadelphia: Lea \& Febiger 1993: p. 203.

[11] Ebenezer J, Rupa V. Preoperative predictors of incudal necrosis in chronic suppurative otitis media. Otolaryngol Head Neck Surg 2010;142 (3):415-20.

[12] Jayakumar CL, Inbaraj LR, Pinto GJO. Preoperative indicators of ossicular necrosis in tubotympanic CSOM. Indian J Otolaryngol Head Neck Surg 2016;68 (4):462-7.

[13] Srinivas C, Kulkarni NH, Bhardwaj NS, et al. Factors influencing ossicular status in mucosal chronic otitis media - an observational study. Indian J Otol 2014;20 (1):16-9.

[14] Tripathi P, Nautiyal S. Incidence and preoperative predictive indicators of incudal necrosis in CSOM: a prospective study in a tertiary care centre. Indian J Otolaryngol Head Neck Surg 2017;69 (4):459-63.

[15] Glasscock ME, Gulya AJ. Surgery of the ear. $5^{\text {th }}$ edn. BC Decker Inc., Elsevier India 2003.

[16] Ingelstedt S, Jonson B. Mechanisms of gas exchange in the normal human middle ear. Acta Otolaryngol Suppl 1966;63(Suppl 224):452-61.

[17] Carillo RJC, Yang NW, Abes GT. Probabilities of ossicular discontinuity in chronic suppurative otitis media using pure tone audiometry. Otol Neurotol 2007;28 (8):10347.

[18] Menon AG, Kaushik M, Nevil V, et al. A comparative study of middle-ear evaluation by otomicroscopy and otoendoscopy in cases of chronic suppurative otitis media. Arch Clin Exp Surg 2017;6:149-55. 